\title{
A Typology for Organizational ICT Practice
}

\author{
Stephen McCarthy \\ Cork Univ. Business School \\ \& Infant Research Centre \\ Stephen.McCarthy@ucc.ie
}

\author{
Paidi O'Raghallaigh \\ Infant Research Centre \\ University College Cork \\ P.OReilly@ucc.ie
}

\author{
Ciara Fitzgerald \\ Frédéric Adam \\ Cork Univ. Business School Cork Univ. Business School \\ University College Cork University College Cork \\ CFitzgerald@ucc.ie $\quad \underline{\text { FAdam@ucc.ie }}$
}

\begin{abstract}
This paper sets out a typology for organizational ICT practice in order to derive a more holistic perspective of sociomateriality and its constituent elements (i.e. humans, objects, and practice). Seminal literature by Parsons and Bourdieu is combined with sociomateriality literature in order to offer insights into the factors that need to be investigated when conducting research into organizational ICT practice. The outlined typology is evaluated through an empirical case study of a connected health ICT project to show how the dimensions of the typology come together and contribute to a better understanding.
\end{abstract}

\section{Introduction}

Modern organizations are under increasing pressure to adapt to rapid change in the internal and external business environment. Consequently, the problems faced by organizations are becoming progressively more ill-structured and complex in nature, which demands dynamic solutions that are capable of addressing them $[1,2]$. Information Communication Technology (ICT) provides a means of supporting an organization in their quest to remain responsive to volatile internal and external change and maintain their level of competitiveness. For instance, the last decade has seen a significant surge in the level of business investment in ICT initiatives such as Big Data analytics, Decision Support Systems, and the Internet of Things. However, the successful implementation of these ICT solutions in organizational practice is far from a straightforward task and instead requires a holistic approach that considers all elements of the system i.e. humans, objects, and practices.

Sociomateriality claims to provide such a holistic approach by offering insights into "the constitutive entanglement of the social and material in everyday organizational life" [3 p. 1435]. The sociomaterial perspective put forward by influential authors such as
Orlikowski $[3,4]$ and Leonardi $[5,6]$ posit that the social is inextricably linked with the material, and one cannot be considered without the other.

Sociomateriality helps explain how the social and the material come together in practice within organizations [7-9]. However, questions have been raised around some of the central ideas proposed by this 'strong' perspective of sociomateriality [10-12]. For instance, calls have been made to reevaluate the perceived ontological myopia of the strong sociomaterial approach which argues that humans and objects are completely indistinguishable from each other $[10,11,13,14]$. In addition, as pointed out by Jones [12], many authors have employed the sociomaterial perspective without a full appreciation of all that it entails, which has in turn limited the empirical and theoretical contribution of sociomateriality to these publications. This issue had led to Sutton [15] criticizing sociomateriality for only adding more academic 'jargon monoxide' and the failure of scholars to provide a clear explanation of its underlying notions $[10,11]$.

In this paper, we relook at the area to propose a complementary approach. We advocate a way of relooking at the sociomaterial assemblage of modern organizational practices. We take a conciliatory stance that seeks to balance the power of a human-oriented perspective and an object-oriented perspective in a way that does not promote one above the other. This means viewing the social and material as interdependent.

We then make what we believe is a much needed return to the seminal literature of Parsons [16-19] and Bourdieu [20-23] in order to regain some of the richness which is missing from sociomateriality literature more generally and from the discourse on practice in particular. We assert that real life practices are a mosaic of intricate patterns which demand an understanding of the systemic factors of an action system and its underlying subsystems (i.e. social, personality, and cultural), as well as characteristics of localized practice. We combine these insights to create a typology that describes the multifaceted lens that scholars could adopt when analyzing organizational ICT practices. 
The theoretical power of this typology is illustrated through descriptions of its application to the healthcare system, and more specifically an empirical case study of a connected health ICT project. The case study is used as an indicative example of the typology's contribution, and derives distinct and valuable findings from empirical data which would be unlikely to emerge from the use of alternative theories. However, this case study is merely one example to show how such a framework may be applied and we feel the principles could be applicable to other organizational ICT practices.

The remainder of this paper is structured as follows: Section 2 provides the theoretical background to our research. Section 3 presents the resultant typology that was developed by the authors. Section 4 presents a discussion based on a case study of a connected health ICT project. Section 5 offers a conclusion.

\section{Theoretical Background}

This section outlines the theoretical background behind our research which draws on theory from the information systems and sociology domains. In particular, our approach is informed by the sociomateriality (c.f. [3, 5-7, 9, 13, 14, 24]), the General Theory of Action Systems [16], and the Theory of Practice [20]. The approach uses this literature in order to explore the social, the material, and how the two are combined together in organizational ICT practice.

The rationale behind combining Parsons' General Theory of Action Systems with Bourdieu's Theory of Practice is to generate a richer understanding of the concept of practice that is seen as central to sociomateriality. We first draw on the General Theory of Action Systems to gain insights into the characteristics and motivational categories of social action. Our attention then turns to the Theory of Practice to understand the temporal-spatial manifold of action in practice and how the social and material come together within a social field $[9,22,25]$. We argue that the two frameworks are complementary and help address some of the limitations inherent in each.

\subsection{Sociomateriality}

There are two main perspectives of sociomateriality categorized by Jones [12]: the 'strong' and 'weak' perspective. The difference between the two perspectives is mostly explained in how each interprets the five principle notions of sociomateriality: materiality, inseparability, performativity, relationality, and practices [12].

The 'strong' sociomaterial perspective assumes that practice consists of two inextricably linked elements: the social which relates to human actors that interact with each other and pursue objectives, and the material which concerns the non-human objects that materialize through practice $[3,8-11,24]$. In particular, the strong view of sociomateriality aims to highlight the central importance of materiality in organizational practice, a notion which is often overlooked in organizational studies [3, 12]. According to strong sociomateriality, the social and material are said to be inseparably linked, and therefore one cannot be considered without the other. In other words, phenomena only come into existence through sociomaterial intra-action in practice, and therefore social and material entities only have inherent properties in relation to, rather than independent of each other $[3,7,10,12]$. The entailments that arise from the social and material are "contingent, dynamic, multiple, and indeterminate", as are the organizational practices that they produce [3 p. 1445]. Furthermore, the relations and boundaries between the social and material are being continuously enacted rather than given, an idea which is otherwise referred to as performativity [12].

Meanwhile the 'weak' perspective of sociomateriality still recognizes the notions of materiality, inseparability, performativity, relationality, and practices, however a different interpretation is presented [12]. In this way it qualifies the notions put forward by authors adopting the strong perspective, such as Orlikowski [3], rather than contradicting them. The main points of departure however are that the weak perspective would reject that the social and material are inextricably linked, and that the properties of objects are only acquired through their enactment $[5,6,12-14]$. The weak perspective also takes a different view of the stability of sociomaterial entanglements and argues that they tend to become institutionalized in certain circumstances. This still allows for entanglements to radically change through the enactment of practice but assumes that entities can also move towards persistence. Finally, the weak perspective disagrees with strong sociomateriality's primary focus on the situated instances of action and asserts that social structure persists beyond the present. This allows sociomaterial practice to be studied both in terms of "macro-level stability and micro-level variation" [12 p. 919].

The main criticism of the strong perspective is that it doesn't allow the social and material to be pulled apart, despite the suggestions that dualism is inherent in the very nature of the sociomaterial assemblage $[10,11,26]$. We take issue with this strong perspective of sociomateriality and contend that the resulting ontological myopia impacts what can be empirically observed when one examines practices. We contend there is a need to deconstruct the sociomaterial assemblage and view the social and material as interdependent rather than inseparable. This allows us to gain more detailed insights into the distinct nature of the 
social and the material in order to arrive at a more complete understanding of sociomateriality as a whole and practice in particular. In this way, the perspective of sociomateriality that we adopt can be categorized within the 'weak' family of thought. We do not deny that the social and material are closely linked; however, we depart from the ontological position of Orlikowski [3] by deconstructing the social and the material in order to gain insight into their distinct characteristics as well as how they come together in practice $[10,11]$.

The next subsection outlines seminal literature by Parsons [16-19] to provide a framework for examining organizational ICT practice.

\subsection{General Theory of Action Systems}

In order to understand the world of humans and objects it is first necessary to analyze the action systems in which they take part [16-19]. Parsons' General Theory of Action Systems [16] provides insights into the characteristics and motivational categories of social action. Parsons takes a holistic view of the systems of actions by recognizing both the motivational significance for individual actors and that of the collective. Social action is said to be guided by three interrelated subsystems: social system, personality system, and cultural system. We will now explain each of these important elements in more detail.

The social system consists of a number of interdependent actors that interact and pursue objectives within given situations that have either a physical or environmental aspect $[16,17]$. The social systems can be analyzed in terms of a 'structural-functionalism' perspective; the structural specifies the elements of a system that can be viewed as constants over a certain ranges of variation in the other elements of the system and the external situation, whereas the functional relates to the issue of mediating between the equilibrium of the system's inherent structure and the changes imposed by the external situation. Normative order is central to social systems and enables social actors to interpret situations based on expectations. The three systems are, therefore, very closely related to one another, and the very existence of a social system depends on the presence of a personality and cultural system.

The personality system refers to the unique identity of each social actor that is interdependent of, rather than constituted by, the role structures to which he/she is ascribed $[16,18]$. The personality system encapsulates the individual's desire for gratification and aversion to deprivation, which thus influences her/his participation in social interaction. Each actor seeks to achieve gratification and avoid deprivation through her/his individual choices of action, as motivated by her/his inherent needs and interests. Needs and interests can be influenced, rather than wholly determined, by the role that an actor assumes. Roles are normatively regulated and involve participation in a structured process of social interaction with role-partners; this assumes that the actor has an obligation for performance in the interaction process. Motivation is also tied to the cultural system as actors can also achieve gratification by taking action that is in line with the dominant set of values. Cultural patterns are therefore maintained through the socialization of the individual whereby societal values are internalized overtime in his/her personality system $[16,27]$.

Finally, the cultural system refers to the complex structure of symbols of expression and meaning, and the conditions of their utilization, maintenance, and change $[16,19]$. These value-orientations and cultural patterns of action which are collectively shared by social actors influence "the motivational aspects of social processes" [28 p. xx]. Culture permeates the very heart of every social system, and influences the behavior of constituent actors, whether they are aware of it or not [16, 27]. According to Schein [27], there are three levels of culture: artefacts, espoused values, and basic underlying assumptions. Artefacts are observable products of the social group such as objects and language which is not always easy to decipher. Espoused values are reflected in all group learnings and develop overtime when values and beliefs initially put forward by visionaries or leaders in an organization are validated through group experience. Only shared values that have been continuously validated as a reliable means of tackling problems will then develop into basic underlying assumptions. Basic assumptions form a bedrock upon which groups take action, and are rarely substituted. Culture is closely related to the social and personality system and is shaped by "leadership behavior, and a set of structures, routines, rules, and norms that guide and constrain behavior" [27 p. 1].

2.2.1. Examples Applied to Healthcare We suggest that any practice ought to be considered in relation to the three systems just described. Table 1 provides an overview of Parsons' subsystems applied to healthcare.

\section{Table 1: Examples of the General Theory of Action Systems}

\begin{tabular}{|l|l|}
\hline Element & Examples for Healthcare \\
\hline Social & $\begin{array}{l}\text { Within a healthcare setting, human actors } \\
\text { such as clinicians, surgeons, pharmacists, lab } \\
\text { technicians, and patients, and non-human } \\
\text { objects such as hospital's patient health } \\
\text { records, medical devices, medication, test } \\
\text { results etc. continuously interact in the pursuit } \\
\text { of healthcare quality [12, 29]. Both actors and } \\
\text { objects are subject to constraints within the } \\
\text { social system such as clinical protocol, }\end{array}$ \\
\hline
\end{tabular}




\begin{tabular}{|c|c|}
\hline & $\begin{array}{l}\text { regulation, standards, and guidelines, but they } \\
\text { are also afforded agency in how they achieve } \\
\text { objectives. For instance, the National Institute } \\
\text { for Health and Care Excellence in the UK has } \\
\text { set out clinical guidelines for managing } \\
\text { hypertensive disorders of pregnancy; } \\
\text { however, clinicians are still permitted to } \\
\text { exercise judgement in certain situations where } \\
\text { it is in the best interests of the patient [30]. }\end{array}$ \\
\hline $\begin{array}{l}\text { Personality } \\
\text { System }\end{array}$ & $\begin{array}{l}\text { Each human actor and non-human object in } \\
\text { the healthcare system possesses a unique } \\
\text { identity that motivates action. Identity is } \\
\text { influenced in part by the role occupied but } \\
\text { there can also be idiosyncratic differences } \\
\text { between the motivations of actors and objects } \\
\text { that are distinct from their role. Rather than } \\
\text { being static, this identity is continuously } \\
\text { unfolding through the process of social } \\
\text { interaction. For example, the identity of a } \\
\text { Clinical Decision Support System (CDSS) } \\
\text { can vary depending on the context in which it } \\
\text { is being used and associated clinical } \\
\text { objectives. A CDSS can be used by surgeons } \\
\text { to review a patient's diagnosis prior to an } \\
\text { operation; alternatively, a GP can use a CDSS } \\
\text { during a health screening to recommend } \\
\text { lifestyle changes to the patient. }\end{array}$ \\
\hline $\begin{array}{l}\text { Cultural } \\
\text { System }\end{array}$ & $\begin{array}{l}\text { The cultural system strongly influences how } \\
\text { human actors and objects interact in the } \\
\text { healthcare system. For instance, clinicians } \\
\text { acquire learnings from past clinical decision- } \\
\text { making processes which can in turn develop } \\
\text { into espoused values, and basic underlying } \\
\text { assumptions [27]. Objects represent another } \\
\text { core level of the cultural system and provide } \\
\text { symbols of expression and meaning within the } \\
\text { patient pathway. Furthermore, machine } \\
\text { learning algorithms in CDSS can provide } \\
\text { opportunities for the learnings of connected } \\
\text { objects to be captured and stored overtime, } \\
\text { along with explicit clinical knowledge. }\end{array}$ \\
\hline
\end{tabular}

One criticism directed towards Parson's theory is that it fails to adequately explain social change, in particular disruptive social change, and power struggles between actors [28]. We assert that this limitation can be adequately addressed using Bourdieu's [20] Theory of Practice which helps describe how actors compete for power and create social change and provides insights into the underlying nature of practice (i.e. the temporalspatial manifolds of action) and the underlying power struggles that exist in the social context.

\subsection{Bourdieu's Theory of Practice}

Bourdieu's [20] Theory of Practice provides a theoretical framework for understanding how human actors pursue objectives within dynamic social contexts. Practice is viewed as the nexus of human activity which means that the social is in a state of constant flux, contingent on how numerous manifolds of actions come together [25]. According to the perspective of prominent practice theorist Bourdieu [20, 22] and Giddins [31], "practices are ontologically more fundamental than actions" and the very being of action is embedded within practice [25 p. 284]. Bourdieu sees practice as comprised of a collectively negotiated set of actions which is governed by a joining together of individual properties such as objectives, interests, and motivations. Therefore, rather than seeing the organization of practice as separate from the determination of individual actions, Bourdieu and Giddens see both as homologous.

Both Bourdieu [20] and Giddins [31] suggest that although actors are subject to underlying continuants in the social context such as social rules, relations, positions (structure), they are also afforded some freedom in how they achieve their objectives (agency) $[13,32,33]$. Similar to Parsons [16], Bourdieu [20] and Giddins [31] aim to reconcile the structuralist and agency perspectives by asserting that structure and agency are closely linked. For instance, Bourdieu [20] proposes that while rules within the social field influence an actor's thoughts and enable or constrain certain activities, actors still have the right to choose between alternative options and decide how they utilize capital. Therefore, power struggles are constituted by the interplay of agency and structure, which occurs in the habitus and in turn can generate social change [34].

Essentially, Bourdieu's [20] framework consists of three interrelated elements which together constitute practice: field, habitus, and capital. The following paragraphs describe these three elements in more detail.

The field element refers to the 'arena' in which interactions between actors and objects take place and the practice unfolds $[32,35]$. Social fields exist as subdivisions within the broader social space and provide explicit and tacit rules, and shared meaning which are specific to each field [20]. A network of actors interact, pursue objectives, and fight for positions of dominance in the social field and develop strategies to maximize their capital within the boundaries of the inherent rules of the social field. The rules that apply are determined by the position that the actor holds in the field and consequently affects what practices can feasibly be undertaken [20].

Habitus is a core element of Bourdieu's [20] theoretical framework and refers to the "ensemble of schemata of perception, thinking, feeling, evaluating, speaking and acting that structures all expressive, verbal, and practical manifestations and utterances of a person" [36 p. 169]. The habitus is socially constructed and affects how actors view themselves, the world around them, and the opportunities and limitations perceived. As a result, the habitus strongly influences 
how actors select and generate actions across similar scenarios [20, 23]. However, the habitus is not static and instead it is dynamically shaped by the surrounding context and is subject to change overtime [34]. As a result, the habitus allows actors to adapt to unforeseen changes and generate strategies that are aligned with change.

Capital refers to the resources that allow an actor to enter a field and occupy a position relative to other actors within the field and social space. Bourdieu [20] asserts that there are four interrelated forms of capital: Economic, Cultural, Social and Symbolic [21, 23]. Each form of capital may be attributed different levels of value depending on the social field under investigation and the rules that are inherent within it. Therefore, one form of capital may be accorded more or less value by actors in the social field. It should also be noted that capital assets are closely interlinked and they can be converted from one form to another. Table 2 describes each form of capital in more detail.

Table 2: Bourdieu's Forms of Capital

\begin{tabular}{|l|l|}
\hline Capital & Description \\
\hline Economic & $\begin{array}{l}\text { An actor's material wealth (i.e. fortune and } \\
\text { revenue) which can be converted into } \\
\text { monetary assets or institutionalized as } \\
\text { property rights. }\end{array}$ \\
\hline Cultural & $\begin{array}{l}\text { Three types of cultural capital: } \\
\text { - Objectivized - cultural capital embodied as } \\
\text { transferable material objects that the actor } \\
\text { possesses. } \\
\text { - Incorporated - an actor's persistent } \\
\text { dispositions that were formed from their } \\
\text { intellectual qualifications or human capital, } \\
\text { and are non-transferable. } \\
\text { - Institutionalized - embodied as a certificate } \\
\text { of cultural competence from a recognized } \\
\text { institution. }\end{array}$ \\
\hline Social & $\begin{array}{l}\text { An actor's network of social relations which } \\
\text { can potentially allow them to access other } \\
\text { resources. Social capital can } \\
\text { institutionalized through a conferred title, } \\
\text { membership of a group / class, or family. }\end{array}$ \\
\hline Symbolic & $\begin{array}{l}\text { Internal and external recognition of an actor's } \\
\text { achievements. Symbolic capital can also be } \\
\text { generated through the conversion of an actor's } \\
\text { economic, social and cultural capital when } \\
\text { they enter a field. }\end{array}$ \\
\hline
\end{tabular}

After: Bourdieu [20]

Of particular interest to our research is Bourdieu's notion of a 'cultural object' which he defines as simultaneously being "a socially instituted material object and a particular class of habitus to which it is addressed" [21 p. 91]. Bourdieu [21] asserts the need to analyze both the effect which the designed object was intended to produce based on its form and the habitus on which it is operated. He argues that the habitus and social field largely influences which material objects the actors perceive as valuable in the social field, and thus affect societal power relations [34]. In other words, practice is created through the combination of the social field, the habitus, and an actor's capital (e.g. cultural object).

2.3.1. Examples Applied to Healthcare We suggest that any practice ought to be considered in relation to the concepts just described. Table 3 applies Bourdieu's Theory of Practice to healthcare and offers examples.

\section{Table 3: Examples of Bourdieu's Theory of Practice}

\begin{tabular}{|c|c|}
\hline Element & Examples for Healthcare \\
\hline Field & $\begin{array}{l}\text { The field of emergency care involves a } \\
\text { multitude of actors such as paramedics, } \\
\text { nurses, doctors, and administrative staff, as } \\
\text { well as numerous objects and other forms of } \\
\text { capital (see Capital row below). Each } \\
\text { subdivision of the social space has different } \\
\text { explicit and tacit rules, and shared meaning. } \\
\text { For instance, in emergency care, the prompt } \\
\text { delivery of urgent patient treatment is } \\
\text { prioritized, whereas in tertiary care the main } \\
\text { focus is convalescence. In addition, the } \\
\text { inherent constraints within each field are } \\
\text { different i.e. journey time in emergency care. }\end{array}$ \\
\hline Habitus & $\begin{array}{l}\text { The habitus enables paramedics to effectively } \\
\text { deal with emergency situations by influencing } \\
\text { their evaluation of the situation at hand, } \\
\text { communication processes, and resulting } \\
\text { choice of action i.e. safely moving victims of } \\
\text { car accident from the crash site. In addition, } \\
\text { the habitus is not static and can change when } \\
\text { necessary which allows paramedics to remain } \\
\text { flexible to changing conditions in the } \\
\text { emergency site. }\end{array}$ \\
\hline Capital & $\begin{array}{l}\text { Examples of capital in the emergency care } \\
\text { setting include: monetary funds to cover } \\
\text { equipment and human resource costs } \\
\text { (economic), access to equipment such as a } \\
\text { defibrillator, piped oxygen system (cultural), } \\
\text { social relations which enable the coordination } \\
\text { of care among specialists in the emergency } \\
\text { department (social), and recognition of an } \\
\text { individual past achievements (symbolic). } \\
\text { Capital allowing actors to enter the healthcare } \\
\text { field, interact, and compete for power. }\end{array}$ \\
\hline
\end{tabular}

The next section introduces a typology for organizational ICT practice that was developed by the authors. The typology was informed by the seminal literature outlined in this section and aims to describe the perspectives that designers could adopt when developing ICT solutions. 


\section{Typology for Organizational ICT Practice}

In order to arrive at a typology for organizational ICT practice, the authors sought to combine the seminal literature from Parsons and Bourdieu to describe practice (that is central to sociomateriality). This aim is to provide a more holistic lens of practice for which considers the perspectives of humans, objects, and practice within organizations. The sociomaterial assemblage is deconstructed into the social, the material and practice and then investigated using the General Theory of Action Systems [16-19] and the Theory of Practice [20, 21, 23]. This can contribute to a greater understanding of practice more broadly through gaining insights into the individual elements and their interdependencies that make it up.

It should be noted that the linkage proposed by sociomateriality between the social, material, and practice is still maintained within this typology. This is similar to the phenomenon of imbrication as described by Leonardi. Where our perspective of sociomateriality differs is that we assert the need to deconstruct the sociomaterial assemblage and re-conceptualize the social, the material, and practice as interdependent elements. We contend that the resulting theoretical lens can provide a far richer set of empirical findings than would otherwise be possible - a richness that can be lost when the social and material are taken as being inextricably linked.

Table 4 outlines some of the limitations of alternative theories that address the characteristics and motivations of social action, and how the social and material come together in practice. This includes the theories of Socio-Technical Systems (STS), the Social Construction of Technology (SCOT), and Actor Network Theory (ANT). The paragraphs that follow Table 4 are dedicated to describing how our typology of organizational ICT practice attempts to address the limitations of these alternative theories.

Table 4: Limitations of Alternative Theories

\begin{tabular}{|l|l|}
\hline Theory & Description \\
\hline STS & $\begin{array}{l}\text { Asserts that the social and technical systems are } \\
\text { interdependent and therefore, both systems } \\
\text { should be considered in tandem and the relative } \\
\text { importance of either should not be presupposed } \\
\text { [37]. A limitation of STS is that it does not } \\
\text { address the nuances of sociomaterial practice } \\
\text { and instead STS primarily focuses on how } \\
\text { abstract social constructs and technical } \\
\text { infrastructure are recursively shaped [5]. }\end{array}$ \\
\hline SCOT & $\begin{array}{l}\text { Explains how social groups shape the } \\
\text { construction of technology, and similarly how } \\
\text { technology influences social groups [38]. A }\end{array}$ \\
\hline
\end{tabular}

\begin{tabular}{|l|l|}
\hline & $\begin{array}{l}\text { limitation of SCOT is that it fails to adequately } \\
\text { consider the impact of power struggles between } \\
\text { social groups; also the SCOT concept of } \\
\text { 'stabilization' overlooks the potential for a } \\
\text { technology artefact to be continuously } \\
\text { reinterpreted during use [39]. }\end{array}$ \\
\hline ANT & $\begin{array}{l}\text { Focuses on how individual actors come } \\
\text { together to form networks and how their } \\
\text { identities and roles are defined within a } \\
\text { network [40, 41]. A limitation of ANT is that it } \\
\text { pays little attention to the role social structure, } \\
\text { politics, power asymmetries, and challenges of } \\
\text { description (i.e. selecting which actors to study) } \\
\text { [42, 43]. }\end{array}$ \\
\hline
\end{tabular}

The aim of our typology of organizational ICT practice is not to supersede these alternative theories, but rather to provide another way of describing practice that addresses some of the limitations of STS, SCOT, and ANT. Our typology for practice allows researchers to consider in tandem the influence of both the systemic factors of action systems, such as social structure, motivations of social action, and culture, as well as localized factors of practice, such as the habitus of actors, social change, and power asymmetries. This contributes to a more complete understanding of organizational ICT practice than previously possible with former methods, and also goes some way to addressing Mutch's [26] criticism of sociomateriality that it directs limited attention towards the notions of broader social structures and power struggles. Furthermore, the typology of organizational ICT practice can support the design of artifacts for improving current systems based on a more thorough account of complex and dynamic environments.

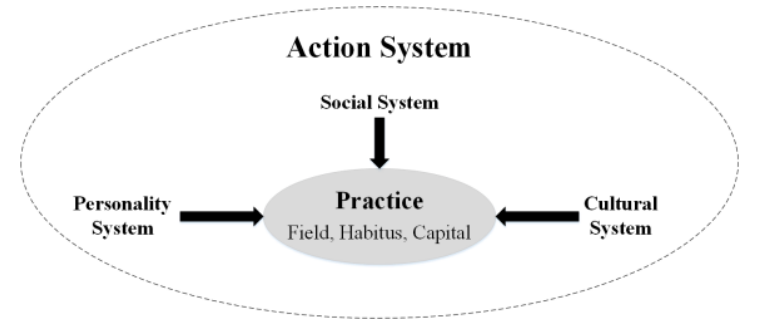

Figure 1: Conceptual Diagram of the Typology for Organizational ICT Practice

Figure 1 presents a conceptual diagram of the typology for organizational ICT practice. Firstly, it shows that practice and its inherent elements such as field, habitus, and capital, are situated within the broader action system. Similarly, the diagram shows that practice, defined as a temporal-spatial manifolds of action where the social and material come together, is affected by the three interrelated subsystems of the action system i.e. the social, personality, and cultural 
system. Therefore, in order to gain a full understanding of practice it is necessary to consider the systems that influence action, independent of any one practice.

Table 5 describes this typology in detail, and highlights its contribution in helping researchers arrive at a more in-depth understanding of sociomateriality.
Descriptions in the table are further informed by the works of Faulkner and Runde [14] and Leonardi [5, 6].

The next section outlines a case study of a connected health design project using the typology for organizational ICT practice as a lens for conducting the sociomaterial analysis.

\section{Table 5: Description of Typology for Organizational ICT Practice}

\begin{tabular}{|c|c|c|c|}
\hline & Field & Habitus & Capital \\
\hline $\begin{array}{l}\text { Social } \\
\text { System }\end{array}$ & $\begin{array}{l}\text { In practice, human actors and non- } \\
\text { human objects interact and pursue } \\
\text { objectives in a social field. They are } \\
\text { afforded agency in how objectives } \\
\text { are achieved but actors and objects } \\
\text { are also subject to the structure of } \\
\text { the broader social system and the } \\
\text { field (i.e. rules, relations, } \\
\text { positions). }\end{array}$ & $\begin{array}{l}\text { The social system influences the } \\
\text { habitus and provides the schemata } \\
\text { for interactions between human } \\
\text { actors and non-human objects. The } \\
\text { habitus helps mediate the field's } \\
\text { inherent structure with changes in } \\
\text { the broader social system, by } \\
\text { adapting to change overtime. }\end{array}$ & $\begin{array}{l}\text { Prior to entering a field, human } \\
\text { actors gain access to capital in the } \\
\text { wider social system which allows } \\
\text { them to achieve objectives and } \\
\text { assume power through practice. } \\
\text { Non-human objects also have a } \\
\text { social life of their own which can } \\
\text { change overtime as they are thrown } \\
\text { away, and recommissioned in new } \\
\text { practices [14]. }\end{array}$ \\
\hline $\begin{array}{l}\text { Personality } \\
\text { System }\end{array}$ & $\begin{array}{l}\text { Each human and object has a } \\
\text { unique identity, and is driven to } \\
\text { action in the field by the } \\
\text { motivations of the personality } \\
\text { system. These motivations are } \\
\text { influenced in part by the role they } \\
\text { assume, as well as personal or } \\
\text { collective interests. }\end{array}$ & $\begin{array}{l}\text { The habitus forms part of the } \\
\text { personality system and molds the } \\
\text { identity of humans and objects } \\
\text { within practice. The habitus } \\
\text { determines how actors select and } \\
\text { generate action which is also } \\
\text { influenced by the associated } \\
\text { motivations of the personality } \\
\text { system that drives action. }\end{array}$ & $\begin{array}{l}\text { Capital can also adopt personality } \\
\text { systems within practice. For } \\
\text { instance, cultural objects have } \\
\text { identities conferred upon them by } \\
\text { humans, based on their form and } \\
\text { function; the personality of objects } \\
\text { is also subject to change overtime } \\
\text { based on its durability [14]. }\end{array}$ \\
\hline $\begin{array}{l}\text { Cultural } \\
\text { System }\end{array}$ & $\begin{array}{l}\text { Humans and objects produce, and } \\
\text { are consciously or unconsciously } \\
\text { influenced in the field by the } \\
\text { values, meaning, symbols, and } \\
\text { assumptions of the surrounding } \\
\text { cultural system. This thus affects } \\
\text { how action are carried out within } \\
\text { the social field. }\end{array}$ & $\begin{array}{l}\text { The habitus is an aspect of culture } \\
\text { that is enacted in practice and } \\
\text { provides a means of expression and } \\
\text { shared meaning. The habitus } \\
\text { impacts actors perceptions, } \\
\text { thinking, evaluation etc. in relation } \\
\text { to the levels of culture i.e. artefacts, } \\
\text { espoused values, and underlying } \\
\text { basic assumptions [27]. }\end{array}$ & $\begin{array}{l}\text { The forms of capital that are valued } \\
\text { in a field are actively shaped by the } \\
\text { surrounding culture. For instance } \\
\text { basic underlying assumptions that } \\
\text { have been validated from previous } \\
\text { experience influence which objects } \\
\text { are perceived as valuable for } \\
\text { undertaking practice [27]. }\end{array}$ \\
\hline
\end{tabular}

\section{Discussion: Case Study of a Connected Health ICT Project}

This section describes the case study of a connected health ICT project to provide an empirical grounding. This case study offers a relevant and rich context for illustrating the theoretical power of our typology, given the complex and multidisciplinary nature of the connected health ICT project.

The connected health ICT project in question was a collaborative effort involving partners from both academia and industry. A multi-disciplinary team of actors came together within the field of a funded connected health project to develop a home-based antenatal system for monitoring the wellbeing of expectant mothers. The developed system integrated a number of different non-human objects including a mobile app, home blood pressure monitor, urine analyzer, and electronic health record. Meanwhile, the project team consisted of twelve human actors including two Principal Investigators, and team members drawn from different institutions and professions, including obstetrics and gynecology, project management, and information systems.

The observations provided in the paper were collected over a period of six months using a field-based methodology. During this time the observer became an active member of the multi-disciplinary team working to define the scope and requirements for the connected health platform. Table 6 describes the findings from this case study in more detail, with findings structured using the typology outlined in the previous section. When we examine the case through the lens of the typology, we notice some interesting nuances which would be unlikely to emerge from alternative theories.

Firstly, the action system had a considerable impact on how localized practice was enacted in the context of 
the connected health ICT project. The project was without precedence, and none of the team had any prior experience of working on a connected health ICT project. As a result, systemic factors from the action system such as the social structure of each partner organization involved in the project, rules set by the scientific funding body, motivational interests associated with the role of each actor, and espoused values and basic underlying assumptions of different cultures influenced the course of social action. For instance, team members from a clinical background were motivated by a 'patient first' approach that focused on the clinical trial, whereas others in the project team were more interested in a 'technology first' approach.

\section{Table 6: Typology for Organizational ICT Practice - Case Study Findings}

\begin{tabular}{|c|c|c|c|}
\hline & Field & Habitus & Capital \\
\hline $\begin{array}{l}\text { Social } \\
\text { System }\end{array}$ & $\begin{array}{l}\text { Practice was affected both by the } \\
\text { structure of the social system and } \\
\text { social field. For instance, explicit } \\
\text { rules were put forward from the } \\
\text { scientific body that awarded funding } \\
\text { for the research. This was } \\
\text { accompanied by more implicit rules } \\
\text { such as around the division of work, } \\
\text { and engagement. Meanwhile, in the } \\
\text { social system, rules were specified } \\
\text { by the involved institutions / } \\
\text { organizations themselves, and } \\
\text { various regulations in the macro- } \\
\text { environment such as data protection, } \\
\text { ethical standards, and medical } \\
\text { protocol. }\end{array}$ & $\begin{array}{l}\text { Each actor came into the pilot } \\
\text { research project with expectations } \\
\text { around the habitus based on } \\
\text { previous engagement with other } \\
\text { research projects i.e. the schemata } \\
\text { of perception, thinking, feeling, } \\
\text { evaluating, and speaking. } \\
\text { However, this changed } \\
\text { dramatically overtime based on } \\
\text { continuous interactions between } \\
\text { actors and changes within practice. } \\
\text { For instance, three requirement } \\
\text { gathering workshops were } \\
\text { organized involving all actors } \\
\text { which helped to form a shared } \\
\text { language and frame of reference } \\
\text { for discussing the project's } \\
\text { objectives going forward. }\end{array}$ & $\begin{array}{l}\text { Each actor possessed valuable } \\
\text { capital acquired in the social } \\
\text { system which allowed them to } \\
\text { engage in practice. For instance, } \\
\text { clinicians possessed cultural } \\
\text { capital such as access to clinical } \\
\text { knowledge, cultural objects (i.e. } \\
\text { medical protocol, clinical } \\
\text { guidelines, and health record } \\
\text { templates), and social capital such } \\
\text { as relationships with patients, } \\
\text { medical practitioners, ethics } \\
\text { committee. Meanwhile, } \\
\text { technicians possessed IT expertise } \\
\text { and had access to cultural objects } \\
\text { such as technology stack } \\
\text { documentation, and associated } \\
\text { medical devices. }\end{array}$ \\
\hline $\begin{array}{l}\text { Personality } \\
\text { System }\end{array}$ & $\begin{array}{l}\text { Each actor had a unique identity } \\
\text { molded by the personality system } \\
\text { which affected their interactions in } \\
\text { the social field. Clinicians were } \\
\text { primarily motivated to engage in } \\
\text { action around the clinical trial, } \\
\text { whereas technicians were more } \\
\text { motivated to undertake action in } \\
\text { relation to systems development. } \\
\text { This also affected the commitment } \\
\text { levels of different groups over the } \\
\text { course of the project. }\end{array}$ & $\begin{array}{l}\text { The personality system had a } \\
\text { strong influence on the habitus of } \\
\text { each actor and motivated which } \\
\text { course of action was selected. For } \\
\text { instance, the habitus of clinicians } \\
\text { prioritized patient interactions over } \\
\text { technology development as the } \\
\text { most important action point in the } \\
\text { project. In contrast, the habitus of } \\
\text { technicians saw the requirements } \\
\text { gathering and agile development } \\
\text { process as the primary course of } \\
\text { action. }\end{array}$ & $\begin{array}{l}\text { Technicians were more motivated } \\
\text { to utilize their institutionalized } \\
\text { capital in the form of mobile } \\
\text { development, technology } \\
\text { integration, security and testing. } \\
\text { Meanwhile, clinicians were more } \\
\text { motivated to utilize } \\
\text { institutionalized capital in the form } \\
\text { of clinical trial management, } \\
\text { documenting new clinical } \\
\text { guidelines, and submissions to the } \\
\text { ethics committee. }\end{array}$ \\
\hline $\begin{array}{l}\text { Cultural } \\
\text { System }\end{array}$ & $\begin{array}{l}\text { Actors came from very different } \\
\text { cultures, and prior to the } \\
\text { commencement of the project no one } \\
\text { had previous exposure to the other } \\
\text { domain of practice. This led to } \\
\text { challenges early on in developing } \\
\text { shared meaning and values. For } \\
\text { instance, knowledge of the patient } \\
\text { pathway was assumed by clinicians, } \\
\text { but technicians were unaware of the } \\
\text { intricate details. A series of } \\
\text { workshops were organized in order } \\
\text { to map this pathway and derive a } \\
\text { shared meaning, values, and } \\
\text { assumptions of requirements. }\end{array}$ & $\begin{array}{l}\text { The cultural system and underlying } \\
\text { assumptions of each actor also had } \\
\text { a strong impact on the habitus in } \\
\text { terms of which course of action } \\
\text { was selected. For example, } \\
\text { technicians had the underlying } \\
\text { assumption that every requirement } \\
\text { had to be fully documented before } \\
\text { development resources could be } \\
\text { expended, whereas clinicians' } \\
\text { underlying assumption was that } \\
\text { prototypes were required before } \\
\text { requirements could be finalized. } \\
\text { This led to some conflict initially } \\
\text { around the course of action. }\end{array}$ & $\begin{array}{l}\text { The cultural system affected which } \\
\text { forms of capital were valued in the } \\
\text { practice. For instance, symbolic } \\
\text { capital was highly valued during } \\
\text { the course of the project. For } \\
\text { technicians, their symbolic capital } \\
\text { was their technical expertise and } \\
\text { achievements in successful } \\
\text { systems development. While for } \\
\text { clinicians it was their clinical } \\
\text { domain expertise, and } \\
\text { achievements in successfully } \\
\text { running a clinical trial. }\end{array}$ \\
\hline
\end{tabular}

Team members were also strongly influenced by their surrounding culture; clinicians prioritized the improvement of patient wellbeing and the implementation of clinical guidelines, whereas 
technicians were more focused on defining system requirements and designing the end solution.

Secondly, factors associated with the localized enactment of practice also had a large impact on the course of social action. Power asymmetries between actors arose from their access to constrained cultural objects such as clinical documentation and medical devices, as well as access to social capital including relationships with patients and ICT suppliers, and nontransferable clinical or technical expertise in the form of institutionalized certificates of cultural competence. In addition, symbolical capital was also valued, including technicians' involvement in previously successful ICT development projects and clinician's experience in delivering prenatal care. These constrained forms of capital along with the habitus, led to the pursuit of conflicting goals in the social field. For instance, clinicians were primarily motivated to utilize their domain expertise within the project, and consequently their level of engagement with the technical aspects of requirements gathering process varied overtime. Similarly, technicians were more preoccupied with utilizing their technical expertise in practice and at times during development may have paid less attention to clinical issues.

As previously mentioned, these findings are unlikely to emerge using alternative theories as a lens for understanding sociomaterial practice. In particular, the typology of organizational ICT practice highlights the impact of social structure, personal motivations, and culture, as well as localized factors, such as changes in the social field, the habitus of actors, and power asymmetries. We feel these insights are essential to understanding sociomaterial practice in order to design artifacts which help improve current systems. Without a proper understanding of these factors, designed artifacts are unlikely to be successful as they will not adequately reflect the elements of practice or larger action system.

The case study shows how the enactment of organizational ICT practice is shaped by both the elements of the action system and practice. Ignorance of these underlying factors can potentially hinder collaboration and create conflict due to issues such as the absence of a shared understanding. The typology of organizational ICT practice helps elucidate these issues by studying the elements of the action system and practice, thus contributing to a better understanding of the underlying factors that can influence the course of social action.

\section{Concluding Remarks}

In this paper we have presented a typology for organizational ICT practice which combines seminal literature from Parsons and Bourdieu with more contemporary ideas around sociomateriality. The resulting theoretical contribution provides empirical insights into the underlying factors which need to be investigated in order to gain a holistic understanding of sociomaterial practice.

One limitation of this paper is that is does not turn attention towards how the outlined typology could be used by designers to create artefacts which will be introduced into organizational ICT practices. Future research will aim to address this limitation by proposing a design lens for organizational ICT practice. In addition, future research will be carried out to apply the typology to other domains.

One noteworthy finding that emerged during our application of the typology for practice to the connected health project was how it described and perhaps even pre-empted the influence of different professions (or tribes) on the practices. In particular, two tribes were identified: that of clinicians from the healthcare profession and technicians from the IT development profession.

One way of understanding the identity of social actor is by categorizing the Community of Practice that they are members of. Communities of Practice, consist of three main elements: domain, practice, and community [44]. Firstly, Communities of Practice require a shared domain of interest in which members commit to. For instance, the domain in question might be IT development or healthcare. In addition, members must continuously or intermittently collaborate, maintain relationships, and share learnings and knowledge within a community environment [44]. Without this sustained interaction, the Community of Practice is unlikely to survive and prosper. Finally, members of the Community of Practice should be actively engage in practice and contribute to a shared resource base. The shared resource base develops overtime through repeated interactions between members and assists them in addresses challenges.

The relevance of Communities of Practices to our case study also merits further research going forward in order to re-examine the empirical evidence in light of this finding.

Acknowledgements: This publication has emanated from research conducted with the financial support of Science Foundation Ireland (SFI) under Grant Number $\mathrm{SFI} / 12 / \mathrm{RC} / 2272$.

\section{References}

1. Conklin, J., Dialogue mapping: Building shared understanding of wicked problems. 2005: John Wiley \& Sons, Inc. 
2. Rittel, H.W. and M.M. Webber, Dilemmas in a general theory of planning. Policy sciences, 1973. 4(2): p. 155169.

3. Orlikowski, Sociomaterial practices: Exploring technology at work. Organization studies, 2007. 28(9): p. 1435-1448.

4. Orlikowski, The sociomateriality of organisational life: considering technology in management research. Cambridge Journal of Economics, 2010: p. bep058.

5. Leonardi, P.M., Materiality, sociomateriality, and sociotechnical systems: what do these terms mean? How are they related? Do we need them? Materiality and organizing: Social interaction in a technological world, 2012: p. 25-48.

6. Leonardi, P.M., Digital materiality? How artifacts without matter, matter. First monday, 2010. 15(6).

7. Orlikowski and Scott, The entangling of technology and work in organizations. 2008: Information Systems and Innovation Group, Department of Management, London School of Economics and Political Science.

8. Suchman, L., Affiliative objects. Organization, 2005. 12(3): p. 379-399.

9. Suchman, L., Human-machine reconfigurations: Plans and situated actions. 2007: Cambridge University Press.

10. Kautz, K. and T.B. Jensen. Sociomateriality-More than Jargon monoxide? Questions from the Jester to the Sovereigns. in ECIS. 2012.

11. Kautz, K. and T.B. Jensen, Sociomateriality at the royal court of IS: A jester's monologue. Information and Organization, 2013. 23(1): p. 15-27.

12. Jones, M., A Matter of Life and Death: Exploring Conceptualizations of Sociomateriality in the Context of Critical Care. Mis Quarterly, 2014. 38(3): p. 895-925.

13. Faulkner, P. and J. Runde, The Social, the material, and the ontology of non-material technological objects. Documento de trabajo, 2010.

14. Faulkner, P. and J. Runde, Technological Objects, Social Positions, and the Transformational Model of Social Activity. Mis Quarterly, 2013. 37(3): p. 803-818.

15. Sutton, R.I. Sociomateriality: More Academic Jargon Monoxide. 2010; Available from: http://bobsutton.typepad.com/my weblog/2010/10/socio materiality-more-academic-jargon-monoxide.html.

16. Parsons, T., The Social system. 1951, London: Routledge.

17. Parsons, T., The structure of social action. Vol. 491. 1937: Free Press New York.

18. Parsons, T., Social structure \& personality. 1964: The Free Press.

19. Parsons, T., The system of modern societies. 1971: Prentice-Hall Englewood Cliffs, NJ.

20. Bourdieu, P., Outline of a Theory of Practice. Vol. 16. 1977: Cambridge university press.

21. Bourdieu, P., The forms of capital, in Cultural theory: An anthology, I. Szeman and T. Kaposy, Editors. 1986: West Sussex, UK. p. 81-93.

22. Bourdieu, P., The logic of practice. 1990: Stanford University Press.

23. Bourdieu, P. and L.J. Wacquant, An invitation to reflexive sociology. 1992: University of Chicago press.

24. Pickering, A., The mangle of practice: Time, agency. \& science. Chicago: University of Chicago, 1995.
25. Schatzki, T.R., Practices and actions a Wittgensteinian critique of Bourdieu and Giddens. Philosophy of the social sciences, 1997. 27(3): p. 283-308.

26. Mutch, A., Sociomateriality-Taking the wrong turning? Information and Organization, 2013. 23(1): p. 28-40.

27. Schein, E.H., Organizational culture and leadership. Vol. 2. 2010: John Wiley \& Sons.

28. Turner, B.S., Preface to the New Edition Introduction: Interpretative Difficulties, in Talcott Parsons "The Social System", B.S. Turner, Editor. 1991, Routledge: London.

29. Doyle, C., L. Lennox, and D. Bell, A systematic review of evidence on the links between patient experience and clinical safety and effectiveness. BMJ Open, 2013. 3(1).

30. NICE, Hypertension in pregnancy: The management of hypertensive disorders during pregnancy, in NICE clinical guideline 107, N.I.f.H.a.C. Excellence, Editor. 2011, National Health Service.

31. Giddins, A., The constitution of society. 1984, Berkeley: University of California Press.

32. Walther, M., Bourdieu's Theory of Practice as Theoretical Framework, in Repatriation to France and Germany. 2014, Springer. p. 7-23.

33. King, A., Thinking with Bourdieu against Bourdieu: A 'practical'critique of the habitus. Sociological theory, 2000. 18(3): p. 417-433.

34. Navarro, Z., In search of a cultural interpretation of power: the contribution of Pierre Bourdieu. IDS bulletin, 2006. 37(6): p. 11-22.

35. Chudzikowski, K. and W. Mayrhofer, In search of the blue flower? Grand social theories and career research: The case of Bourdieu's theory of practice. Human Relations, 2011. 64(1): p. 19-36.

36. Krais, B., Gender and symbolic violence: Female oppression in the light of Pierre Bourdieu's theory of social practice. Bourdieu: critical perspectives, 1993: $\mathrm{p}$. 156-177.

37. Mumford, E., The story of socio-technical design: Reflections on its successes, failures and potential. Information Systems Journal, 2006. 16(4): p. 317-342.

38. Bijker, W.E., Of bicycles, bakelites, and bulbs: Toward a theory of sociotechnical change. 1997: MIT press.

39. Klein, H.K. and D.L. Kleinman, The social construction of technology: Structural considerations. Science, Technology \& Human Values, 2002. 27(1): p. 28-52.

40. Callon, M., The sociology of an actor-network: The case of the electric vehicle, in Mapping the dynamics of science and technology. 1986, Springer. p. 19-34.

41. Latour, B., Reassembling the social. Hampshire: Oxford University Press, 2007.

42. Walsham, G., Actor-network theory and IS research: current status and future prospects, in Information systems and qualitative research. 1997, Springer. p. 466480.

43. McLean, C. and J. Hassard, Symmetrical absence/symmetrical absurdity: Critical notes on the production of actor-network accounts. Journal of Management Studies, 2004. 41(3): p. 493-519.

44. Wenger, E., R.A. McDermott, and W. Snyder, Cultivating communities of practice: A guide to managing knowledge. 2002: Harvard Business Press. 